\title{
Live mediation: Performing concerts using studio technology
}

\author{
Yngvar Kjus and Anne Danielsen, University of Oslo
}

\begin{abstract}
The use of computers is continuously changing the sound of records but also increasingly challenging established forms of live concert aesthetics. So what becomes of creativity and expressivity in the live performance? In this study, we present an artistoriented approach to this question through interviews with artists invested in performing studio works on stage, as well as improvising musicians using studio technology in their concerts. We find that challenges to creative authorship and expressive agency are constantly negotiated through evolving practices of up- and down-scaling particular aspects of studio works on stage, as well as designing technological set-ups tailored to individual forms of improvisation. While these practices challenge deep-rooted notions of the 'right' or appropriate bond between musician and music, the appropriation of studio technology in live performance has clearly become an integral part of many artists' continual exploration of their musical agency.
\end{abstract}

\section{Introduction}

Artists are increasingly performing live with technologies that have long been primarily used in the recording studio, including sound recording, editing and processing functions. This performance practice has a long trajectory that stretches back to early forms of turntablism in experimental music in the 1920s (Holmes 2012, p. 45). In the 2000s, however, we see a much larger range of musicians who are using digitised studio technology to create and rework their own music on stage. Some artists reanimate their studio works, including those in the domain of electronic dance music (EDM); others use studio-related tools to improvise and create new music, including those in the experimental jazz milieus. It is, in other words, a relatively broad trend that is presently incorporating new forms of music mediation into live performance, with profound implications for the artists, their music and their audiences. In this article, we will investigate the creative and expressive opportunities (and limitations) associated with bringing studio-related technologies to the stage. While our focus is on the use of digital technology on stage, we will also take the opportunity to address the larger questions of how live music is created in general, and what its truly live elements in fact are. Studio works have generally been the focal point of popular music research. In this way the article also responds to a dearth of research into live music-making in this field, particularly from the perspective of the performers.

We will begin with a brief discussion of the predominant perspectives on live music performance in the existing literature. We will then engage with the creative and expressive conditions of live performance in relation to those of studio production. Our comparison will focus on the relationship between artists' intentions, actions and sounds, and on the role of technology in linking among them. The main body of the article is an interview-based study with ten musicians who integrate studio-related 
technologies into their concerts in different ways; through this study, we will investigate the ongoing processes through which studio work and live performance converge.

\section{Creativity and expressivity in live performance}

What is live music performance? The paradigmatic form of live music, argues Peters (2001), entails the shared presence of artists and audiences in the same place at the same time. Concerts thus afford specific conditions for the creation, expression and experience of music, including, among others, the assumed simultaneity of production and perception. This 'immediacy signature' is perhaps best captured by the individual artist who sings to an audience: what the audience hears emerges directly from the performer's body at the moment of its making. This classic mode of live performance, however, still reveals processes of mediation, because this sound source (the voice) is subjected to sound processing (the space's acoustics) as it is transmitted to the audience. This relatively benign type of mediation is generally overlooked by the audience, though musicians routinely use the acoustic capacities of performance venues as artistic resources. The intervention of new technologies, however, always forces both artists and audiences to reconcile themselves with a new array of uses and effects. One early example is the use of microphones for 'crooning', which facilitated, in turn, a form of intimacy from the stage that some found inappropriate (Scannell 1996); another is the transition from acoustic to electric guitars (and amplifiers), which introduced a new sense of distance (and even alienation) between some musicians and their fans (Frith 1986). As people tried to make sense of this new technology, the operative concepts of 'acoustic' and 'electronic' instruments emerged (Randel 2003), while the concept 'acousmatic' was introduced to describe music where the sound had been separated from its source (Schaffer 2006).

Perhaps the most substantial technological intervention related to sound mediation is the innovation of recording technology, which allowed sounds produced at one place and time to be heard elsewhere at other points in time. As Auslander (2012) has argued, it was the use of records that made it possible (and necessary) to distinguish performances as 'live' - a term that was therefore reliant upon its mediated counterparts. While the labeling of live music as live was initially a response to the temporal distance between sounds and their sources, the concept of acousmatic music instead addressed the spatial disjunction. Toynbee (2000, p. 71) has argued that a conservative impulse against the separation of sounds from their sources hampered the exploration of new recording technology, so that generally, in the first half of the twentieth century, it was primarily traditional, linear concert performances that were taped. In the second half, however, new recording opportunities were discovered and increasingly embraced, along with a plethora of tools and techniques for editing and manipulating sound (Brøvig-Hanssen 2013).

In the field of popular music, the Beatles were among the first artists to explore innovative use of recording technology, promoting the studio-produced album as the primary artistic vehicle of white Western music in the late 1960s. The creation of new sonic forms was welcomed by fans, cultural commentators and academics alike, and their descriptions indicate that the perception of live performance also changed substantially along the way. Eisenberg (2005[1987], p. 90) writes, 'The ideal is no longer live music, but some technologic Platonic form . . . Rock music in concerts tends to sound like a crude impersonation of a record'. Gracyk (1996, p. 84) adds, 'Studio recordings have become the standard for judging live performances'. The cultural ascendance of recorded constructions even led Auslander (2008 [1999], p. 42) to argue 
that 'live actors are only pale reflections of the mediatized representations that dominate the cultural landscape'.

As music researchers turned to in-depth studies of the new sound technology, studio work became the focal point. Théberge (1997, p. 216) notes, 'Recordings allow the musicians to distance themselves from the act of performance and create "impossible music", that is, music that could not otherwise be conceived or performed'. Toynbee (2000, pp. 86-87) finds, 'Without the benefit of the studio-larynx it was musicians on stage who would struggle to emulate the recorded sound rather than the other way around'. He considered the Beatles' decision to stop touring in 1966 to be a public acknowledgment of this tendency, and Zak (2001, p. 55) describes their shift as follows: 'They began to work exclusively in the studio, creating works that were never intended for live performance'.

However, even as the Beatles stopped going on tour (a decision that has also been attributed to tour exhaustion and abundant records sales), a great many other artists continued to play on stage, as well as in the studio. In fact, there arose a deep-rooted practice of bringing music back and forth between studio and stage which many popular musicians routinely perpetuate to this day. This, in turn, begs the question of whether we ought to engage with live performances as alternative renderings of musical content, rather than dismiss them because the music might have originated elsewhere. To assess exactly what is brought to the stage and how it fares there is to focus on the musicians' creative and expressive processes rather than their artistic objects, and this is a potentially productive avenue of investigation. This effort also foregrounds the fact that everything that appears on stage has a prehistory: it originates in other places and times, and in this sense is always-already mediated.

It is crucial to note that the ways in which music reaches (and is renewed on) the concert stage are at least partly governed by genre conventions and expectations. We might label a certain group of genres as 'song based' - that is, the audience assumes that the artist - or other artists - has composed the music in question elsewhere and is simply presenting it on stage. This mode is well established in popular music ranging from disco acts to singer-songwriters, and it can be nuanced according to the degree of individual interpretation that is introduced at the moment of performance. We might label another group of genres as 'improvisation based' - that is, the audience anticipates a spontaneous performance, though playing techniques and repertoires of certain stock phrases will usually be prepared in advance. This is a common practice in jazz and certain avant-garde musics and will be nuanced according to the specific expectations associated with exactly what should be uniquely created during or through the live act. Even in this case, however, we would do well to recall Ytreberg's general insight that 'if the scripting of some aspects of the performance has to be reduced . . . there will be a drive towards more comprehensive scripting of other factors' (2006, p. 437). We might label a third group of genres as 'sample based' - in this case, the audience acknowledges that the artists will be replaying and remixing existing recordings on stage. This mode of performance has long been prevalent in DJ culture and characterises contemporary EDM as well.

The rise of the last group has depended on what we for simplicity will call studio technology, which enables the live recording, editing and processing of music. Since the 2000s, a growing assortment of musicians has utilised studio technology innovatively in the live performance of their own music, as we will see further below. Over time, artists have found themselves able to not only make music in new ways in the studio but also create and sustain new conditions for performing it on stage. The domains of studio and stage musicianship have, in fact, converged in tandem with the rise of mobile and 
flexible music production centres and (later) digital audio workstations with software designed for live performance as well as record production (such as Ableton Live, see also Montano 2010). Studio practices have been integrated with stage performance to varying degrees of complexity. On the one hand, pre-produced elements can simply be replayed; on the other hand, the artists can record, compose and process everything that the audience hears during the performance. Hybrid forms have also evolved, so that the sounds that emerge via editing and mixing techniques can, for example, run parallel to sound sources that are not subjected to those techniques (live singing, for example).

What we discuss here is but the most recent turn in what has been a long-lasting migration of technology from studio to stage; Knowles and Hewitt (2012) have suggested a chronology ranging from the analogue mixing of dub reggae in the late 1960s to the live recording and mixing of contemporary electronica artists like Imogen Heap or Nine Inch Nails. Explorations of the aesthetic potential of computer-generated sounds and structures have an even longer history within art music, where such elements introduced variable and indefinite elements to the live realisation of musical compositions (Emmerson 2007). The use of new technology has thereby challenged a host of aesthetic assumptions in Western music, including those involving completeness in works of art.

New technology has had a provocative critical potential within the sphere of popular music as well. For example, Richardson (2011, p. 30) has analysed live performances with looping technology that, according to him, articulate 'anxieties about the visual in acoustic music' and allow 'audiences to reflect on the nature of contemporary mediatized experience'. Auslander has highlighted the potential of computer music to challenge established ideas of 'visible causality', which he finds particularly relevant thanks to the 'Western privileging of the sense of sight' (2013: 607). These various technological challenges to aesthetic regimes also have social dimensions, with stakes for the artists involved. When the relationship between source and sound is contested, it can be thought in one sense to alienate the artist from his or her art. In Western culture, therefore, new technology has long been considered a threat of sorts (Benjamin 2008[1936]) - an example of the alienation that Marx warned about when labourers would be distanced from the fruits of their labour (Hesmondhalgh and Baker 2011). The fear of technology and industry has permeated whole genres of popular music, providing the ideological rationale behind rock musicians claiming authorship of their records through the performance of them, as recorded, live on stage (Grossberg 1993). Other pop genres have embraced technology as empowering, and the rise of digital technology, in particular, has been associated with a general cultural democratisation and the ability of artists to gain more control over the processes of production. Technology's appropriation has likewise contributed to a much-publicised blurring of roles such as musician, record producer, mixer and engineer. Scholars have so far tracked the exploitation of these possibilities in terms of studio work alone, charting the actual gains and risks from the viewpoint of the artists (see, for example, Frith and Zagorski-Thomas 2012). It is past time for similar studies in the realm of stage performance as well.

Among other things, we might look at the creative and expressive conditions of live performance on stage, as opposed to in the studio. Creativity could be understood as an inner process through which music is conceived, even when it is inspired by external impressions. Expressivity could be understood as an outward-oriented process through which musical intentions are communicated to others. These processes are intimately linked, of course: creativity requires some form of expression, while expressivity depends on the source that inspired it. This bond is reflected in Williams's definition of 
artistic work as the act of 'conveying experience' (1975[1961], p. 54)-one through which experience is given a form that others can share via the senses. The ways in which artists create and express music vary a great deal, of course, but one consistent condition is their context in time and space. The presence of an audience, of course, sets the stage apart from the studio. Rehearsal studios, that is, are usually places for the selfabsorbed musical exploration of playing techniques as well as compositional elements. In recording studios, artists shape sounds into an aesthetic object to be heard by other people at other times and in other places. Listeners will only perceive the final expression, but they might there find clues to the artist's creative process as well.

The concert stage, on the other hand, provides quite different conditions for creativity and expressivity, in psychological, perceptual and social terms. First, artists have the opportunity to convey their musical intentions through an expression that reaches the audience directly and continuously, more or less, from moment to moment. Second, the live expression encompasses not only sound but also any other perceivable aspect of the artists' presence and agency. Sounds, physical movements and visual elements offer many possibilities for guiding and adjusting the audience's interpretation and appreciation of the music. Third, the live concert has the potential to allow anyone present, fellow musicians as well as audience members, to influence the making and shaping of the music. This social organisation of the performance can impact its various aspects and goals substantially. Turino (2008, p. 90) distinguishes between presentational performances, where everyone is focused on what the artist does, and participatory ones, where everyone is engaged in music making and focused on their own contributions. These are ideal types, however - the first anchored in Western art tradition and centred on the author, the second embedded in more collectivistic traditions. Presentational and participatory ideals present different challenges for technology and live music. In the former type, anything intervening between the artist and the music could be taken for a threat to the artist's primacy or hegemony; in the latter, technology could come to hinder the participation of all of those present. In practice, however, most presentational performances contain participatory elements (from polite clapping to enthusiastic dancing), and visa versa. A specific combination of presentation and participation is often a defining trait for a musical genre, in fact, which interested artists must learn to negotiate.

It is clear, then, that creative and expressive investments on stage depend upon their social framework, but another basic condition of musical performance is the means through which intentions can be made perceivable. At a live event, this latter process can potentially involve the entire sensory apparatus, encompassing the sound, sight, touch, smell and feel of a performance. Apart from the performing body's own sound sources, including the voice or the hands clapping, for example, artists inevitably look to external sources with which to express their musical inclinations and inspiration. This introduces the 'mandate of instruments', which invites a closer look at the more specific potential roles of technology in linking artists' intentions, actions and sounds.

In acoustic instruments, Jensenius argues, 'action-sound couplings are based on mechanical laws, while the action-sound relationships found in electronic instruments are designed and constructed electronically' (2013, p. 181, italics added). He then notes that while a digital piano, over time, can establish a relationship between action and sound that feels natural, 'it is questionable whether our perception of them may ever be as strong as that of a coupling'. On the other hand, studies have indicated that acoustic instruments can be made to consolidate compelling intimate and intuitive links between creativity and expressivity. As the saxophonist Harold Ousley observes: 'Sometimes the ideas come from my mind and I have to find them quickly on the horn, but other times 
they come from my fingers' (Baily 1991, pp. 150-51). For Clarke (2005, pp. 171-72), Ousley's observation illustrates how the artist can develop a form of 'sensorimotor intelligence' through the long-term use of their instrument which can also fill a 'choreographic' function in live performance, indicating where he or she is headed to both co-musicians and audience members. In parallel, other studies have indicated that the action-sound relationships of electronic instruments represent a very different musical resource. Toynbee describes a type of unpredictable and 'solitary experimentalism ... . in the company of machines', then quotes the musician Larry Heard' on his experiences with his drum machine and synthesiser: 'I just hit a chord with two hands on the keyboard and the Juno 6 arpeggiated it. I could never recreate it, it was just something that happened in the midst of me experimenting, and I got it on tape' (Toynbee 2000, p. 96, citing Trask 1996, p. 36). Others have lamented the expressive limitations of instruments with computer-designed interfaces, which leave 'very little in the way of physical performance cues to link a performer's actions with the sonic output' (Andean 2011, p. 128). The sound, in turn, offers comparatively less intuitive information about the action, challenging the ability of the audience to 'distinguish the sounding parts of various performers, or to identify the output of a particular individual agent' (ibid., p. 129).

While these accounts reflect fairly common stances regarding the opportunities and limitations of digital music technology, there is little systematic or empirical research on the agency and experiences of the artists who use it. In this article we will focus on a specific type of action-sound relationship, that of studio-related technologies which are used to record, manipulate and process sounds rather than to create them, as well as on the performance practices and forms of musicking into which the technology is introduced.

\section{Approaching performers}

For this study, we explored music mediation and live performance specifically through interaction and conversation with performers. Rather than concerning ourselves with musical works as aesthetic objects, then, we studied artists as musical subjects. In this way, we have borrowed the socially oriented approach of ethnomusicology, which has been little used on more recent forms of technology-intensive musicking. Studies of digital musical means, and what is sometimes called 'computer music', have to this point mostly focused on the technology itself, and its musical affordances (Dean 2009). However, in-depth interview-based studies of artists could arguably represent a substantial source of insight into the use of new musical tools, in terms of concrete practice as well as the creative and expressive experience.

Still, we must be aware of the obvious limitations of ethnographic approaches, particularly regarding their applicability across meaningful cross-sections of the subject population. Musicians have different backgrounds and skills, as well as individual artistic goals and projects, and their investments in new technology are likely to be just as diverse. Rather than securing representative findings, then, the goal here is to identify practices and experiences which are essential to the artists that are studied, and which hopefully could spur the analysis of contemporary musicians elsewhere as well. In order to identify and compare different practices, we sought a relatively diverse group of artists whose common denominator was significant and long-term experience with studio-related technology in live performance. We prioritised artists who were active, visible and ambitious in their musical fields and recruited ten of them in the end to form a group that was evenly divided between the two basic models of live performance 
discussed above (song based and improvised). It should be noted, however, that several artists in both groups have a wider palette of musical experience than what is described and discussed in the context of this article.

The first group-Fred Ball, Kristoffer Carlsen, Hallvard Wennersberg Hagen, Hanne Hukkelberg and Bendik Hovik Kjeldsberg - was primarily asked to talk about their experiences with working out and recording their compositions in the studio before bringing them on stage. The second group-Øyvind Brandtsegg, Mari Kvien Brunvoll, Trond Engum, Maja Ratkje and Tone Åse - was primarily asked to talk about their experiences with fully improvised live electronic performances. ${ }^{i}$ Most of these informants started out as traditional instrumentalists or vocalists but have since turned to new technologies to explore alternative musical roles and practices, both in studio and on stage. All have music as their primary area of work, and the relevance of our research topic to their professional lives might explain why they were interested in the study. Furthermore, all of the artists are active in Norway, where this research was carried out, although some were based abroad and others regularly toured in other countries.

The interviews were carried out between 2012 and 2015 through four standalone interviews and two group interviews involving three artists apiece. Group interviews, of course, are sometimes subject to consensus-seeking dynamics (Lunt and Livingstone 1996), so the separate interviews helped to introduce alternative experiences and perspectives. Before we conducted the interviews, we prepared a semistructured interview guide which was partly informed by our own concert observation. The interviews, in fact, followed the structure of putting on a concert, starting with the considerations that led up to the event, then continuing on to the act of live performance. The interview questions specifically addressed distinctions between studio work and live performance, as well as the ways in which the use of studio-related technologies affects creativity and expressivity on stage. We formulated the questions in an open manner in order to encourage varied perspectives, and interviewers actively followed up on responses from informants. We conducted the interviews in Norwegian and translated selected quotations into English ourselves. When cited, the source is added in brackets so as to allow the reader to relate the insight to the individual responsible for it (who could then be heard live or via recordings of concerts online).

\section{Adapting studio works to the stage}

A well-established procedure in popular music is first to compose songs, then to record them in the studio and, later, to perform them live. Five of our informants worked this way but also integrated recording technology into their composition as well as their performance practices. Common to this group is the use of a home- or project-based studio, developed and operated by the artists themselves. These artists combined hardware and software for sequencing, recording, editing and processing into a setup that was customised to their specific purposes, typically with a personal computer at its heart. This studio could be used to record and program sounds, edit and rework them in various ways and compose them into the ultimate song. Artists described this as an immersive creative and expressive process, one involving 'hour after hour of detailed work' (Hagen), where 'you have such an incredibly microscopic focus'(Ball) which facilitates 'listening for different sounds and trying out different layers' (Hukkelberg). As we shall see, their individual investments in the studio are in different ways closely linked to the subsequent performances on stage. 
Hukkelberg, who is part of the singer-songwriter tradition, has used studio technology to explore various acoustic sound sources, including traditional ones, such as voices and string instruments, and unconventional ones, such as bicycle-wheel spokes and trash cans. On stage, she recreates that process of exploration, but even though she tries to handle several of the sound sources herself, she must recruit a band to play them as well (the extent of which is determined by, among other things, the expected income from ticket sales). There are never enough people to play all of the parts on the record, so she must play some from a computer as well, which brings up the following considerations:

In my band we have eternal discussions about whether the Mac should be visible on stage or not, and how much it is okay to have on it. Generally, if it is just a small pulse in the background, it is okay to play from the machine, but not if it is a very special sound. Then you miss the actual movement, [and] to us that feels like cheating.

Before concerts, then, Hukkelberg decides which sounds are most central and must be played and expressed visually. She therefore limits the use of studio technology to the replay of certain background elements, the handling of which is also placed on the periphery of the stage.

Our two next informants, Hagen and Kjeldsberg, participate in innovative electronica milieus, combining elements from the realm of jazz with electronic dance music (among other things). They have used their home studios to explore electronic soundscapes, using electronic sound sources, including drum machines and synthesisers, and/or heavily manipulated samples of acoustic sounds. They describe the process of creating these different sounds as 'designing' and 'almost like office work', clearly distinguishing it from most acoustic playing. Bringing this kind of studio product to the stage is a complex challenge, as Kjeldsberg, our youngest participant, notes:

I had worked with the piece in the studio for a long time, and thought that 'I know this', but when the concert approached, I was like 'What have I done? I have to play this live!' It was very time consuming to make small changes in the piece, which had to be made in order for it to work live. I had to figure out what I was able to do live and what to have on the Mac-so it was a lot of thinking and not much fun to start with.

Hagen, the more experienced artist, describes the transition to the stage as a routinised practice of deconstruction:

It is a deconstruction of the things that have been composed, which are then broken down into elements that are triggered live. I split things up-prepare the music to be manipulated and reworked. I check that all the loops are right and they can be time-stretched in the ways I want during the concert. And I check the effects, many things like that.

Through this process of deconstruction, and the ensuing reconstruction, artists not only identify the most important sound elements from the studio-based recording but also those parts that are suitable for processing and editing on stage. While some sequences are set up simply to be replayed, others are readied for live manipulation, and it is the extent of this manipulation that determines what hardware and software are brought 
from the studio to the stage. A laptop that facilitates audio synthesis via a sequencer always forms the basis of a set-up that often incorporates an evolving assortment of effects, plugins and processing software. One of the reasons for testing new technology is Hagen's stated desire to 'present something fresh and explore the music further', while another is the fact that the studio-designed sounds 'might sound bad through the PA system of the concert venue, requiring real-time adjustments'.

Last but not least, both of these artists usually bring with them certain acoustic sound sources to be played live, even though they might not have been played acoustically on the record. In deciding 'what will work live', both agree on the need for a live drummer. This added sound source provides them with elements to sample, process and rework live, allowing them to carry out key aspects of their distinct form of musicking on stage. The goal is that the audience 'hears something interesting'; in general, they are 'more concerned that it sounds good than that it looks good'. They are well aware that the audience cannot see or process exactly what they are doing with their various computers and controllers, and sometimes they try to compensate by pressing the button with a gestural flourish when triggering an audible change. Still, as Hagen says, 'I don't ever want to pretend or make something extra out of something that isn't real', and he hopes instead that the audience simply appreciates that 'we are there, together with our music, exerting control over it and the way it sounds'. These artists have also encountered audience members who ask, 'Can I put my jacket here?' or 'Can you put on another song?' in the middle of sets, as though they were not performing something live or were DJs rather than musicians. They therefore acknowledge the need for some basic level of expressivity on stage-one that is at least partly provided by the addition of acoustic instruments with explicit action-sound couplings, such as the drums.

The pop/electronica projects of Carlsen and Ball differ from the work of the aforementioned artists by more explicitly seeking to captivate the audience and harness more of a dance-music aesthetic. Like Hagen and Kjeldsberg, though, they create their music in the first place through programming, recording, editing, and sound processing. In live performance, though, they very much want to transmit the exact grooves and hooks they developed in the studio, or even intensify them:

I try to recapture what was on the record, but I think live, you have to be a bit more emotionally extreme - if you are doing a ballad, you do it very ballad-like, if you know what I mean-you go completely low. And if you're going to do something that is very energetic, you have to take off completely. (Ball)

Before going on stage, then, they also decide which elements can be simply replayed, but only in tandem with a host of live performers, usually including a vocalist, keyboardist, and drummer. Carlsen explains:

We want to pump up the atmosphere and get people dancing. It gives more energy when you see the musicians working. We do notice that other acts have more on [prerecorded] tracks than we do, but when everything becomes electronic, I think it is necessary to compensate, using things like dancers, costumes and other visuals as well.

On stage, live performers exaggerate actions that are visually expressive of the sound, but this must be carefully coordinated with the many key sound elements that are created in advance. These pre-produced elements obviously dictate the temporal 
structure of the live performance, including song tempo and transitions, which the live musical instruments must match: 'We play with click tracks in the ear, which everyone relates to' (Carlsen). This rigorous level of control has its down side: 'The risk and maybe the stupid thing of using tape is the thing with "Should we do one more chorus?" You can't be spontaneous - everything is laid down in the plan, right?' (Ball). Artists must therefore minimise the creative use of studio-related technology on stage, and the ability to improvise with acoustic instruments is also limited by this necessary orchestration of the pre-produced and the live.

A striking feature of the above discussion is that studio technology appears to have afforded all five artists with substantial agency in the composition of their records, but its utility on stage is more questionable. There are also interesting correlations between what they record, edit and mix in the studio, and what they bring or do on stage. Hukkelberg uses her studio to capture and combine the sounds of various acoustic instruments and objects, which was also her longtime goal on stage. Earlier in her career as a live performer, she explained, she tried to play and process many sound sources at the same time, but she found it overwhelming. For her, then, the ideal had become a 'technological platform that allows me to connect with myself and the audience, and to express the music the way it is meant to be, rather than stealing it away from me'. In concerts, she now prioritises individual acoustic sound sources based on their ability to build a sturdy bridge between her initial, studio-based creative process and what she expresses to the audience from the stage.

Hagen and Kjeldsberg use their studio facilities to design and refine more fully electronic soundscapes - a practice that they also want to bring to the stage. They therefore cultivate very creative opportunities to recompose, process and rework their studio tracks in real time. Both artists remain aware that this form of performative creativity is difficult to express visually, but they hope the music is worth it.

Lastly, Carlsen and Ball use the studio to create catchy, danceable tracks that also impact their creative transition to the stage. While the live performances of the other artists are largely in a presentational mode, Carlsen and Ball seek participation in in the form of dancing. When preparing their performances, then, they do not prioritise the opportunity to be musically creative on stage but instead try to maximise the expressive and 'energetic' potential of the recording. What they bring to the stage, in pre-recorded as well as live forms, is intended to stimulate the perception and interpretation of the music as festive and thereby trigger collective forms of musicking, such as dancing.

These cases demonstrate the significance of the musical intentions that are invested in and communicated through recorded works when those same artists present them on stage. But what about when there is no preceding record?

\section{Live improvisation with studio technology}

Half of our informants rely on improvisation as their primary musical technique, which they practice in the studio as well as on stage. For them, the arrival of project-based, mobile studio technology has enabled the making of records in alternative locations with unique acoustic and atmospheric qualities (churches or industrial buildings, for example), which inspires them in different ways. Happily, this technology also offers the opportunity to make several takes and edit them afterward in the studio, affording 'much greater control over the outcome than on the concert stage, where the sound of it all is much more unpredictable' (Åse). As opposed to the artists above, these five improvisers all start with the assumption that they will create and play all elements of 
their live performance then and there. Studio-specific technology simply does not factor into the live calculation: 'If I don't create sounds, there is nothing for me to sample' (Ratkje); 'Just replaying something you have already made ... then you might as well leave [the] stage, really' (Brunvoll). Three of the improvisers are accustomed to offering solo performances in which their voices prompt their live recording, composing and processing activity. Another plays guitar, and the last usually participates in ensembles in which he primarily works with sounds made by others. With their joint focus on improvisation, these five artists are less diverse in terms of genre than the previous five, and their live performances are explicitly presentational, assuming the audience's full attention to the emergence of music on stage. Closer investigation, however, reveals considerable variations in just how these artists improvise, and how they use studiorelated technology to help.

On the night before a concert, Brunvoll assembles her technological setup, then makes time to "sit and research, listen, improvise and put together new and old parts, and visualise the job I'll do'. She prepares musical phrases that can be recorded, looped and processed during the performance, and practices with her tools to achieve her desired results. Her live set-up includes a vocal microphone that is connected to a sampler and a guitar pedal with a variety of effects, as well as a second microphone which she does not subject to sound manipulation. She reserves this microphone for acoustic sound sources, including a kalimba, enabling herself to 'wander, in a way, in and out of acoustic and electronic landscapes, making the one pull the other'. Her setup allows her to loop and manipulate several layers of her own voice and instrumentation but also revert to a non-manipulated mode of expression. Brunvoll thinks her audience generally grasps these shifts and hopes that, 'as long as the audience is attentive, even small gestures with buttons and levers can be expressive'. She has found that the audience's degree of focus depends on the concert venue, however, and particularly on whether the audience will be seated or standing: 'When people come and go-for instance, at festivals - it is like the small things don't get attention, [and] you must talk with capital letters'.

Åse, on the other hand, does not prepare set musical phrases in advance but rather creates with her technological setup on the spot. Her equipment consists of two samplers, two effect boxes, a mixer, and a laptop with Ableton Live to control various computer-based plug-ins and a Hadron Particle Synthesizer, and she refers to the whole arrangement as her 'instrument': 'In the days preceding a concert, I get into contact with the instrument and rehearse where the sounds are, so that I have a sense of a vocabulary and can feel ideas coming'. Although her voice is her only sound source, Åse points out that the technology allows her to 'achieve a vastly greater and entirely different sounding expression' than she could hope to do without it. She is well aware, however, that some audiences find her less visually expressive than other singers as she operates the buttons of her machines. She tries to compensate for this by becoming as comfortable as possible with her technology, so that she can immerse herself physically in the music making: 'If I am approaching a crescendo, for instance, I don't plan a gesture to express it, but my body makes one all the same. The sound inside me tells me to move in certain ways'. After establishing a strong connection between her inner sense of the music and the sound that emerges through the technology, she relies on her body to supply visual cues during the performance.

The third vocalist, Ratkje, does not pre-prepare phrases either ('for me, knowing what to sample would not be interesting'), nor does she seek extensive command over her technology, because she wants her performance (and her technological setup) to be 
capricious, original and fresh. She is very aware of the strategic import of the technological setup in this regard:

You can use technology that is super easy to handle or extremely advanced, sometimes having full control and sometimes not at all. So you can put the level [of control] where you want. I put it where it is a little insurmountable. Because I think it is very exciting, and because I don't like to repeat myself when I improvise.

Ratkje had a version of the advanced audio software Csound programmed for her specific needs (by Øyvind Brandtsegg). It is operated via MIDI controllers, with faders, buttons and keyboard, and facilitates many simultaneous processes 'from loop control to fragmenting or changing the sound itself'. While Ratkje allows parts of her setup to serendipity, she remains very interested in charting the sonic qualities of the live performance venue. Ratkje ideally spends at least four hours at the stage in advance, working with the local sound technician to chart which frequencies of sound produce feedback and which might 'make the room sing along'. As her live performance begins, she commits herself to exploring the extreme range of sonic forms that emerge through her technology, and via her environment. Ratkje is not worried about the connection between her actions and her sounds, which she establishes early on: 'They see that I open my mouth and [they] hear the sound coming out'. She acknowledges, however, that the link tends to blur later in her performance, when she might replay a sample that was recorded earlier in the concert, sometimes even backwards and/or with added sound effects. For her, that is, challenges to the action-sound connection comprise key creative and expressive resources. Her set-up allows her to transform her voice into sounds that she does not necessarily anticipate, 'which may express various moods, from euphoria to aggression, that even I am not always able to identify'. She does not see herself as 'immersed in the emotions' but rather cultivates an analytical distance regarding everything she manages to conjure up through technology. 'I want to convey a sense of ambivalence', she says, celebrating the fact that the audience ultimately finds it 'incomprehensible that my voice turns into all those other sounds'. Exploring the points of transition and limbo between her human voice and the 'inhuman' and uncanny voice of the machine is, in fact, particularly gratifying to her.

The remaining two artists, as mentioned, do not use their voices as the primary sound source but instead play an instrument or process the sounds of others. Engum connects his guitar to various sound processing units which are wired into a mixer program on his laptop; he operates the software via external controllers. When he performs with others, he wires them into the system as well. He often introduces new modules of sound processing at concerts, and 'if it feels successful, these might be integrated into my long-term set-up'. As a devoted guitarist, he is interested in 'gradually expanding the instrument' and even transcending established and conventional action-sound links regarding the guitar. This is a performative challenge: 'Sometimes it can take a few seconds or more from when I hit the strings of the guitar till the processed sounds come rolling along, making it hard for both audience members and co-musicians to understand what's coming'.

This timing challenge is even more acute for Brandtsegg, who bases his performance on the sounds he receives from other band members:

When someone makes some kind of musical initiative, you don't have many seconds to route that impulse to the right place. Sometimes I live-sample from 
three or four different sources to five or six different effects, making it a challenge to know just what is going to blow out via the PA and into the concert hall.

Brandtsegg therefore continually explores technological opportunities and innovations that afford expedient and flexible sound management. He concedes that many of the functions in his instruments did not exist twenty years ago, 'making it necessary to experiment to find the best solutions'. Using them in live performance is the ultimate test of whether they work fast enough. The core elements of his setup are a computer with a mixer program (called Reaper) which facilitates various sound-processing plugins. Brandtsegg programs these plug-ins individually in order to achieve specific types of sound transformation, then operates them via external controllers 'which all are growing, as I haven't managed to find a good enough interface yet'. Brandtsegg's engagement in the design of all of these stages of sound mediation has triggered an important creative (and practical) realisation: 'My instrument, in fact, extends right out to the large loudspeakers - it is part of one comprehensive chain of sound signals'. The last links in this chain are the PA system and the acoustics of the venue: 'Although I do not operate the PA, I can use it-for instance, when I feel the sub-basses below the stage, I can work with those sounds'. He does acknowledge the limitations of his changing and expansive musical apparatus:

I often think about the physical, intuitive unity that an acoustic instrumentalist develops with an instrument that is constant, year after year. I simply have too many buttons and plug-ins that I continuously redefine. I have to prioritise between developing my instrument and developing an internalised relationship to it. For my musicianship it is essential to push the instrument further-this is my form of musical progression.

He tries to 'compensate' for this ephemerality by rehearsing with new set-up elements before concerts, and by practicing visible gestures as he operates them, so as to give the audience a sense of what he is doing. The artist thereby continuously negotiates the uneasy relationship between his actions and his sounds, in creative as well as expressive terms. Sometimes the relationship breaks down, leaving both the artist and his audience confused about these sounds' origins and building blocks. Other times, however, new forms of musical interaction appear.

These participants in the study all refer to a continuum ranging from improvisers who establish a stable technological setup that approximates the constancy of acoustic instruments to improvisers who seek unstable and continuously evolving technology. Exploring the relationship between themselves and technology represent a substantial creative resource for all of them, but while some use the technology to explore their own musicality (e.g., Brunvoll and Åse), or expand a traditional instrument (e.g., Engum), others focus more specifically on their exploration of the musicality of the technology (e.g., Ratkje and Brandtsegg). Exploration is, nevertheless, not only the governing principle of their creative process but also the overarching expressive form of their live concerts, which tend to progress from or build upon basic elements, usually emerging from acoustic sound sources, and end up in the increasingly complex electronic layering and processing of sounds. Again, some of the artists prepare key elements of this musical excursion in advance, retaining a measure of control over which aspects of their own musicality that will expose, while others let the exploration of the technology structure the concert. 


\section{Discussion: Live mediation}

The artists in our study have all seized upon the opportunities offered by affordable, mobile and multifunctional technology to record, edit, process and otherwise manipulate the sounds in their music. In the studio, they immerse themselves in the time-consuming creation of exactly the musical expression they want; on the stage, they construct their music in real time while also controlling the 'chain of sound signals' (Brandtsegg) in new ways. At earlier stages of popular music history, recording technology contributed to a division of labour. As Toynbee (2000, p. 98) points out, 'The very separation of functions can produce a sense of alienation, particularly for producers cut off in their studios'. In our study from the second decade of the 2000s, however, we found that studio-related technology is used by artists and musicians to realise their own musical vision, unrestricted from the band-instrument constellations upon which they would otherwise depend. This was particularly striking among the improvising vocalists, who use their technological tools to extend the reach of their voices into a bigger soundscape.

When we zoomed in on the use of studio-related technology in live performance, however, we also saw the emergence of new challenges and especially the danger of this 'alienation'. In truth, what an artist is able to create in the studio can be hard to recreate on stage, and what one actually creates on stage can be difficult to perform in a manner that reveals the creative process and supports the artist's ownership of it. Artists are clearly developing skills with regard to adapting recordings and/or technology from the studio to the stage in ways that accommodate creative authorship and expressive agency. For half of our informants, this translation involved upscaling certain elements of their studio work and downscaling others. The improvisers, on the other hand, were more invested in designing a technological set-up that provided them with a fitting range of possibilities on stage.

The de- (and re-)construction of recordings appears to be intimately linked to the way in which artists prioritise the presentational and participatory dimensions of the live event, respectively. When the aim is to present their own creativity, the most significant tools involved in their studio work are brought to the stage. For some, that means acoustic instruments and objects, so Hukkelberg brought several musicians on stage to supply more of the sound sources even as she replayed certain elements from a computer-based technological array. For others, that means the technology necessary to rework and refine electronic sounds, so Hagen and Kjeldsberg confronted the challenge of identifying which electronic elements were suited for what forms of real-time manipulation, and which elements could be adjusted in advance and replayed from the machine. They preferred this approach to the recruitment of additional computer-based musicians to execute all the sampling, processing and editing of the studio work. They also chose to replace certain electronic elements, such as the drum track, with acoustic ones, however, to foreground specific parts of the recorded track and also provide sounds that could be reworked electronically on the fly.

The artists who aimed for more participatory concerts tended to bring more coperformers and instruments on stage, while also replaying longer or larger sections of their recorded tracks using machines. The increase in live performers is not intended to recreate or reflect the creative process but to heighten the energy of the live event and engage the audience, in particular through dancing. Ironically, these artists' efforts to preserve the danceability of their pre-produced music sometimes hurt their ability to adjust the performance to the festivity of the audience, for example by doing 'one more chorus', because the timeline of the live performance is fixed. 
A tendency common to all of our informants who used their recorded music as a point of departure for performing live, however, is that they summoned more musicians on stage than they ever did in the studio. So, while the use of new technology may have reduced the number of musicians necessary in the studio, it introduces new requirements for performers on stage. Our study demonstrated that such co-performers needed to be able to fulfil specific creative and expressive functions on stage, in keeping with the lead artist's recorded vision.

For the improvisers, the question was not how much of the recording to bring from the studio, but how much technology, and how to relate to it when they were on stage. They had to cultivate special skills in adjusting their technological setups to suit their individual musicality and artistic agenda. While a common trait for the improvisers was their profound interest in the sounds that might emerge on the spot, an equally common one was their commitment to preparing and tailoring their setups in advance. This is in keeping with Ytreberg's aforementioned argument that, even as the preparations regarding certain aspects of a performance are reduced, 'there will be a drive towards more comprehensive scripting of other factors' (2006, p. 437). Some of these artists designed their setups in a way that accommodated intuitive forms of temporal sequencing, so Brunvoll used hers to 'wander, in a way, in and out of acoustic and electronic landscapes' during a concert. Others sought an advanced, complex and unpredictable technological setup so as to address their own particular sensitivities to the encounter between their technology and the acoustics of the concert space.

Common to all ten informants was the fact that they exerted considerable agency in adapting what they brought from the studio to the temporal, spatial and social settings of the live performance. Several of the artists pointed out the challenges of latency and invisibility with regard to studio-related technology, which records and manipulates sounds rather than creates them. It is striking that most of the artists-even those who had created everything electronically in the studio-tended to use acoustic sound sources on stage, either integrating them with the recorded elements or manipulating them in real time. An obvious benefit of acoustic instruments, which are based on mechanical laws, is their clear coupling of action and sound (Jensenius 2013, p. 181). The visible handling of the instrument is therefore a reliable indicator of the sounds that are about to emerge, as well as what those sounds might mean to their maker. As Clarke (2005, p. 172) points out, artists who have played an instrument for a long time develop intuitive ways of combining the 'ergonomic' aspects of this manipulation with the 'choreographic' aspects of live performance. With sound manipulation technology, however, this connection is no longer non-reflexive, as was demonstrated by statements such as 'I don't ever want to pretend' and 'in my band we have eternal discussions' regarding the (dis)connection of action and sound. We saw resistance to both excessive dramatisation as well as excessive minimisation of the coupling of action and sound in the operation of a computer, for example, on stage.

Incorporating acoustic instruments into the live performance is one way to negotiate the performance's overall relationship between actions and sounds. In this regard, the human voice and the drums were prioritised by our informants. Once a strong linkage such as these is established, it is correspondingly more likely that the audience will associate other stage sounds with the artist's actions as well, even when they are less perceptible or engaged with non-acoustic objects. This had particular relevance to the solo artists, who remain the only human sound source on their stages, as well as the improvisers who began with a few discernable sound sources and then moved on to much more complex soundscapes. The exact nature and extent of this priming effect, however, as well as the perception and interpretation of other forms of 
mediated agency, demand further investigation using audience members, rather than performers, as participants.

The link between musician and music is complicated further by the artists who manipulated the action-sound couplings of acoustic instruments in new ways. The conception of what a human voice is (and can express) can be stretched to the limit (and beyond), and instruments with otherwise well-established action-sound relationships, such as the electric guitar, can be undermined by layers of mediating technology that confound those relationships. On an overarching level, these kinds of innovations confront key conventions of Western music, including the cultural authority of "visible causality' (Auslander 2013, p. 607) and deep-rooted notions of the appropriate or authentic bond between artists and their art. In their daily musical practice, however, several artists in this study had clearly integrated new technology in order to develop and exercise their creative agency.

Though the pervasiveness of studio technology on stage may suggest the abandonment of the entire notion of 'live performance', we think otherwise and applied an artist-oriented approach in order to reshape the questions being asked. The practices related to what might be called 'live mediation' are evolving fast-among our ten informants and many other artists in a range of neighbouring genres - but growing increasingly omnipresent and impactful as well. Further studies of other genre communities and individual practices are needed to enhance our understanding of the new relationships between stage performance and traditional studio work.

\section{Acknowledgements}

The authors wish to thank the informants for their contributions to this study, and the anonymous reviewers for constructive comments. We also thank John Durham Peters and Simon Emmerson for inspiring feedback. This research was supported by the Research Council of Norway through the project Clouds and Concerts. Mediation and Mobility in Contemporary Music Culture [grant number 205265].

\section{References}

Andean, J. 2011. 'Ecological psychology and the electroacoustic concert context', Organized Sound, 16/2, pp. 125-33

Auslander, P. 2008 [1999]. Liveness: Performance in a Mediatized Culture, $2^{\text {nd }}$ edition (New York: Routledge)

Auslander, P. 2012. 'Digital liveness: A historico-philosophical perspective', A Journal of Performance and Art, 34/3, pp. 3-11

Auslander, P. 2013. 'Sound and vision: The audio/visual economy of musical performance', in The Oxford Handbook of New Audiovisual Aesthetics, eds. J. Richardson, C. Gorbman and C. Vernallis (Oxford: Oxford University Press), pp. 605621

Baily, J. 1991. 'Some cognitive aspects of motor planning in musical performance', Psychologica Belgica, 31, pp. 147-62 
Benjamin, W. 2008[1936]. The Work of Art in the Age of Mechanical Reproduction (London: Penguin)

Brøvig-Hanssen, R. 2013. 'Music in bits and bits of music: Signatures of digital mediation in popular music recordings', $\mathrm{PhD}$ thesis, University of Oslo

Clarke, E. F. 2005. 'Creativity in performance', Musicae Scientae, 19/1, pp. 157-82

Dean, Roger T. 2009. The Oxford Handbook of Computer Music (Oxford: Oxford University Press)

Eisenberg, E. 2005[1987]. The Recording Angel: Music, Records and Culture from Aristotle to Zappa (New Haven: Yale University Press)

Emmerson, S. 2007. Living Electronic Music (Farnham: Ashgate)

Frith, S. 1986. 'Art versus technology: The strange case of popular music', Media, Culture and Society, 8, pp. 263-79

Frith, S., and S. Zagorski-Thomas. 2012. The Art of Record Production: An Introductory Reader for a New Academic Field (Farnham: Ashgate)

Gracyk, T. 1996. Rhythm and Noise: An Aesthetics of Rock (Durham, NC: Duke University Press)

Grossberg, L. 1993. 'The media economy of rock culture: Cinema, postmodernity and authenticity', in Sound and Vision: The Music Video Reader, eds. S. Frith, A. Goodwin and L. Grossberg (London and New York: Routledge), pp. 185-209

Hesmondhalgh, D. and S. Baker. 2011. Creative Labour: Media Work in Three Cultural Industries (New York: Routledge)

Holmes, T. 2012. Electronic and Experimental Music. Technology, Music, and Culture, $4^{\text {th }}$ edition (London and New York: Routledge)

Jensenius, A. R. 2013. 'An action-sound approach to teaching interactive music', Organized Sound 18/2, pp. 178-89

Knowles, J., and D. Hewitt. 2012. 'Performance recordivity: studio music in a live context', Journal on the Art of Record Production, 6, web

Lunt, P. and S. Livingstone. 'Rethinking the focus group in media and communications research', Journal of Communication 46/2, pp. 79-98

Montano, E. 2010. 'How do you know he's not playing Pac-Man while he's supposed to be DJing?': Technology, formats and the digital future of DJ culture', Popular Music, 29/3, pp. 397-416

Peters, J. D. 2001. 'Witnessing', Media, Culture and Society, 23/6, pp. 707-23 
Randel, D. M. 2003. 'Electronic music', The Harvard Dictionary of Music (Cambridge: Belknap Press)

Richardson, J. 2011. An Eye for Music: Popular Music and the Audiovisual Surreal (Oxford: Oxford University Press)

Scannell, P. 1996. Radio, Television and Modern Life: A Phenomenological Approach (Oxford: Blackwell)

Schaeffer, P. 2006. 'Acousmatics', in Audio Culture. Readings in Modern Music, eds. C. Cox and D. Warner (London and New York: Continuum), pp. 76-81

Théberge, P. 1997. Any Sound You Can Imagine: Making Music/Consuming

Technology (Middletown, CT: Wesleyan University Press)

Toynbee, J. 2000. Making Popular Music: Musicians, Creativity and Institutions (London: Arnold)

Trask, S. 1996/1992. 'Jazz angles', in History of House, ed. C. Kempster (London: Sanctuary)

Turino, T. 2008. Music as Social Life: The Politics of Participation (Chicago: University of Chicago Press)

Ytreberg, E. 2006. 'Premediations of performance in recent live television: a scripting approach to media production studies', European Journal of Cultural Studies 9/4, pp. $421-40$

Williams, R. 1975[1961]. The Long Revolution (Harmondsworth: Penguin)

Zak, A. 2001. The Poetics of Rock: Cutting Tracks, Making Records (Berkeley: University of California Press)

${ }^{\mathrm{i}}$ Further information about the artists can be found on their websites: Fred Ball: http://fredballmusic.com, Øyvind Brandtsegg:

www.ntnu.edu/employees/oyvind.brandtsegg, Mari Kvien Brunvoll: www.kalleklev.no/artists/1/1442.html, Kristoffer Carlsen: www.eikmusic.com, Trond Engum: http://thesoundbyte.com/, Hallvard Wennersberg Hagen:

www.xplodingplastix.com, Hanne Hukkeberg: www.hannehukkelberg.com, Bendik Hovik Kjeldsberg: https://myspace.com/bendikbeat, Maja Ratkje: http://ratkje.no, and Tone Åse: www.toneaase.no/. 